\title{
Effective Technology Strategy for Shale Plays
}

\author{
Susan Smith Nash \\ Director of Education and Professional Development, American Association of Petroleum Development, American Association of \\ Petroleum Geologists, USA
}

Copyright (C) 2015 by authors, all rights reserved. Authors agree that this article remains permanently open access under the terms of the Creative Commons Attribution License 4.0 International License

\begin{abstract}
This paper presents the results of an analysis of the current state of shale play development in the United States to determine the recent advances in the understanding of reservoir behaviors and the most effective uses of new techniques and technologies. It emphasizes reservoir optimization, and the application of new technologies and techniques to reduce costs and to improve recoverability of hydrocarbons to improve ultimate recoverable reserves. It specifically addresses issues of decline curves, stranded pay between laterals, stacked pay logistics, and pad drilling. In addition, the presentation looks at sweet spot optimization, effective investments, hydraulic fracturing, and geomechanics. In a low price environment, with extreme volatility, the paper also examines strategies employed by companies to preserve their assets and recoverable reserves, which include drilling but not completing and alternative stimulation strategies.
\end{abstract}

Keywords Petroleum Geology, Oil and Gas Exploration, Hydraulic Fracturing, Petroleum Engineering, Horizontal Drilling, Independent Producers, Geochemistry, Enhanced Oil Recovery, Shale Gas, Oil Shale

\section{Introduction}

Steep decline curves, inadequate drainage, and variable production histories have been a major concern in shale plays in North America. In times of low petroleum as well as natural gas prices, reservoir optimization with the best possible use of technology and new techniques becomes "mission critical." For many producers, the easiest approach would be to emphasize bypassed and/or stranded pay where the cost to recover the marginal reserves (since the infrastructure is already in place) may be as low as $\$ 20$ per barrel. In this case, it is important to recognize that there exists bypassed and stranded pay in multi-stage hydraulically fractured wells where there are "sweet spots" (that is to say, preferentially enriched zones within the heterogeneous reservoir rock) that were not adequately produced due to a number of factors. Many of the factors have to do with the fact that the formations being produced are extremely heterogeneous and also that the actual well design and execution can be less than ideal due to factors such as inadequate "plug and perf" stimulation, drilling out of zone when geosteering, proppant and fluid problems, fracture interference, and poor cluster efficiency. First, however, it is necessary to know how to identify and target the bypassed and stranded pay. Then, one must review approaches to effectively targeting and producing the pay, ranging from whipstocking the laterals, sidetracking, refracturing, pinpoint perforating, and radial drilling. Further, it is necessary to build a knowledge base and good teams to effectively analyze a reservoir, gather the correct data, build a model, and develop a drilling and production plan.

\section{Part I: Next Phases of Shale Play Development}

Optimizing shale plays is no longer just a North American concern. In China's Sichuan Province, which contains the Fuling Field, companies such as Sinopec, in conjunction with Chengdu University of Petroleum, and the State Key Labs, and partners such as Chevron and ExxonMobil, are diligently seeking ways to overcome the very significant logistical challenges. Further, the conventional wisdom of "bigger is better" is challenged as costs escalate.

Across the border from prolific Eagle Ford shale wells in south Texas, teams of Mexican geologists have focused on the potential for exploiting the stratigraphic equivalents in northern Mexico. (1, p29,31,33,39) The newly passed Energy Reform has opened the possibility of significant investment in these plays. But, no one wants to repeat costly errors, or to persist in using technologies and approaches that result in vast percentages of the oil in place being left behind.

For the global community of geoscientists, it is necessary join forces to solve technical problems. Certainly there will always be issues of intellectual property and also ownership of property, or market-making events in the case of a public company. Those issues notwithstanding, it is necessary to find ways to accelerate the development of and transfer of knowledge. 


\section{Stranded Pays: Between the Laterals}

Despite efforts, the decline curves for oil and gas production from shales continues to be steep and rapid. Within 36 months, many wells are no longer producing, despite the fact that a single horizontal well may penetrate many sweet spots directly, and in other cases, may drill through the edge of a lenticular, isolated sweet spot "pod." The sweet spots that are on the edge of the laterals are not easily produced, and as a result, there may be pay that's left behind. It could be considered "stranded pay."

Stranded pay" denotes pay that might be technically recoverable, but it is not economically recoverable. Here are a few key points:

- The concept of "stranded pay" is not reserved for mature fields or uneconomic isolates

- There is stranded pay between and alongside laterals.

- To recover stranded pay in within the laterals, it is best to return to the first laterals drilled in a pad, which are mainly depleted ones. It is important to begin with the depleted laterals in order not to disturb ongoing production

- "Offsets" or "whipstocks" out from the laterals to enter the sweet spots that contain "stranded pay" often identified by microseismic or geochemical methods (2)

For example, a pad may have 10 laterals, if the pad has been there for 3 or 4 years, it is likely that at least one or two of the laterals is no longer productive, since declines tend to be steep and are essentially at less than 10 barrels of oil per day within 36 months.

For example, some formations are extremely heterogeneous, and in a 5,000 foot lateral, there may be a $300-400$ foot section that is on the edge of a very nicely fractured "pod" that has excellent accessible porosity thanks to induced fracture. However, the lateral just grazed the edge of it. It did not drain well.

The pod (lenticular unit) has what we can safely call "stranded pay".

The question becomes: how can we recover the oil and/or gas that has been left behind due to geosteering errors, poor communication, and low connectivity of permeable zones?

That is where innovative drilling and completion can play an important role. The crux of the challenge is this: how is it possible to recover the oil and gas we know is in relatively porous and permeable zones on the edge of a lateral?

\section{Sweet Spot Optimization: Whipstocked Laterals}

The "stranded pay" is sweet spots. The can be imaged fairly accurately when there are XRF, XRD, microseismic, geochemical analyses, mudlogs, and more available. The fact that they're available after the fact of completion could present an advantage of sorts if it is possible to re-enter the lateral, and then whipstock off into the core of the sweet spot.

The ideal approach is to drill a directional offset through a lateral, and/or whipstock into a highly fractured sweet spot (fractured in the original completion), it will not be necessary to re-stimulate the well by refracturing it, which would include using chemicals such as hydrochloric acid to dissolve some of the carbonates and clear the facture networks. (3)

To summarize, here are some of the techniques needed in sweet spot optimization:

- Better integration with sequence stratigraphy, geochemistry, imaging, XRF, etc.

- Under development: Whipstocking the Sweet Spots

- Whipstock directional drilling for better penetration of sweet spots

- Whipstock off the lateral where microseismic indicates a fracture pod

- Packers or sliding sleeves to perf within the whipstocked part of the lateral?

\section{Cost Reductions}

If one looks at the Analyst Day presentations of companies that are operating in shale plays, you'll find a common theme, which tends to center on cost reductions. Companies such as SandRidge Energy have been able to reduce drilling, completion, and operating costs significantly. (4)

Some companies have invested heavily in core studies in order to focus their efficiencies in the completion / stimulation phases. Others have looked ahead to stacked pays, and have invested in taking the time to study the other uphole potentially producing zones.

- Fracturing efficiency improvements (better pressure management, frac height control)

- Proppant, fluid, water management, pad drilling, logistics improvements

- Water management / water re-use

- Stacked pays (Bakken, Permian, Oklahoma)

\section{Cost Intensifications}

In a very counterintuitive manner, some companies such as Continental Resources, have aggressively attacked the concept of technology and efficiencies and have decided to invest in additional technologies that will improve recoverability, and will allow additional zones, new laterals, new stages, and whipstocks to be utilized. So, their costs seem to be very high, but in the end, the ROI could be significantly higher if the ultimate recoverable reserves can be increased by an additional $5-10$ percent, at a relatively low cost.

Here are a few of the technologies that cost more money, but pay off in the end.

- Microseismic sensor arrays (10-well installation)

- 3D visualization

- Goal: improve hydraulic fracturing, determine frac heights

- Find where the sweet spots are (lenticular units with communication)

- Return to drill additional laterals, or whipstock into the heart of the pods

Managing Drilling Fluids to Minimize Formation Damage and Optimize Completions 
Addressing the problem of steep decline curves requires a multi-pronged approach. One of the reasons for the steep decline rate in shale plays is due to the clay mineral content and the fact that clay minerals can swell or bind with other chemicals, which can destroy permeability and porosity. Thus, both drilling and hydraulic fracturing fluids can cause the clay minerals to behave in a way that creates formation damage.

Developing a water-based mud that inhibits shale swelling is a critical part of making sure that there is minimal formation damage in drilling a shale well, and also in developing completion fluids.

Shale inhibitive drilling fluids help reduce swelling of clay minerals, which are grouped in five groups: kaolinite, smectite (montmorillonite), illite, chlorite, and vermiculite. Smectite is the most reactive to water, while clays such as illite having a low Cation Exchange Capacity (CEC) swell through surface hydration. (5)

Additives include $\mathrm{pH}$ controllers, fluid loss additives, viscosifiers, salt, and oxygen scavengers. Inhibitors include chrome and ferrochrome lignosulfonate, potassium chloride, amines and polyamines, and methyl glucoside, depending on the type of clay minerals in the shale. (6)
- Surface hydration: typically occurs in clays that have a low CEC values such as illite. Cation substitution takes place in illites within the outer tetrahedral layer.

- Ionic hydration: hydration shells formed around the compensating ions, and occurs in clays with high CEC values.

Osmotic hydration: due to the difference in salinity fo the shale rock fluid and the drilling fluid. If the shale rock fluid salinity is higher than the drilling fluid, the shale will hydrate.

Understanding the CEC helps develop the "best fit" drilling fluid and determine the best mud formulations. Water-based muds (WBMs) with additives (including glycol) are options, as well as oil-based muds and those with potassium chloride. (7)

\section{Refracturing}

Although hydraulic fracturing techniques continue to evolve, many operators who have drilled shale plays have come to realize that many wells have not been stimulated in a way that is effective. The main problems are fracture interference and cluster efficiency, which result in the fact that there are significant portions of unstimulated pay in typical shale play completions such as in the Woodford. (3)

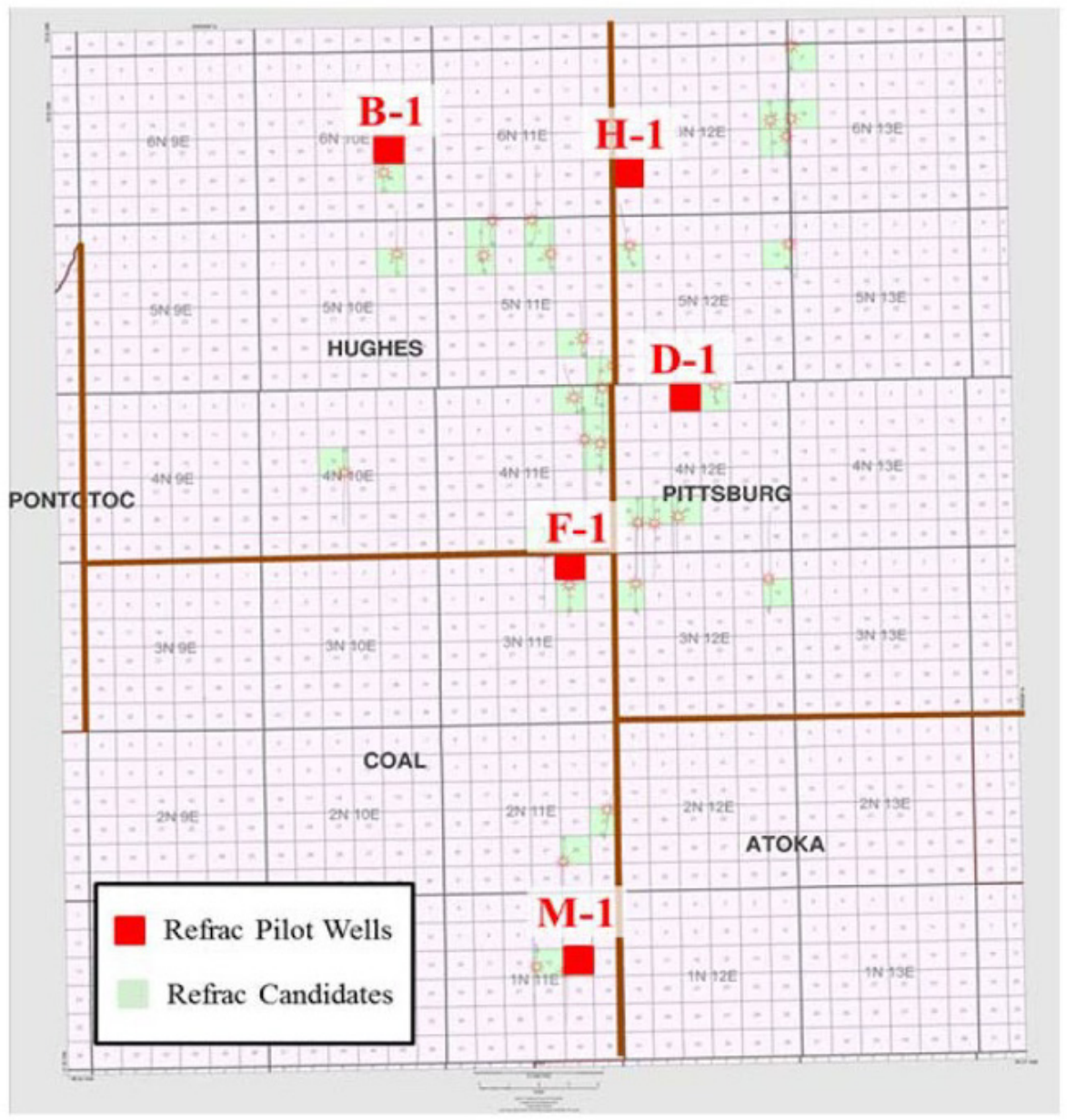

Figure 1. Location Map of Re-fracturing Pilot Wells (3) 


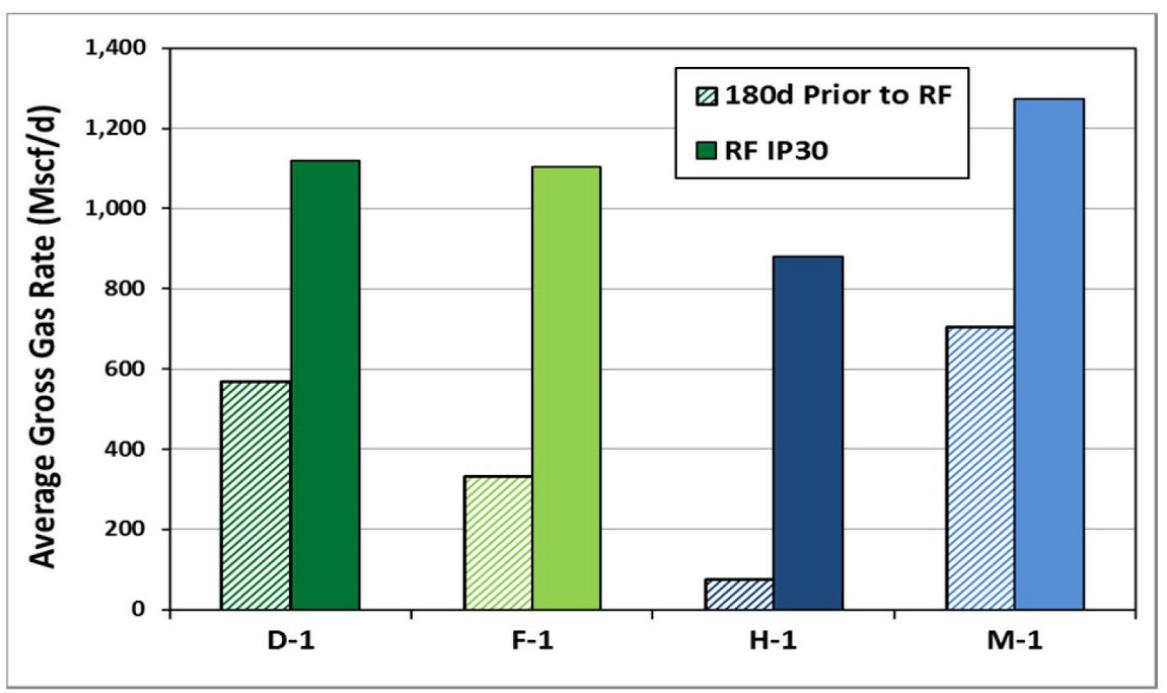

Figure 2. Plot of Pre-Re-fracturing Production Rates (3)
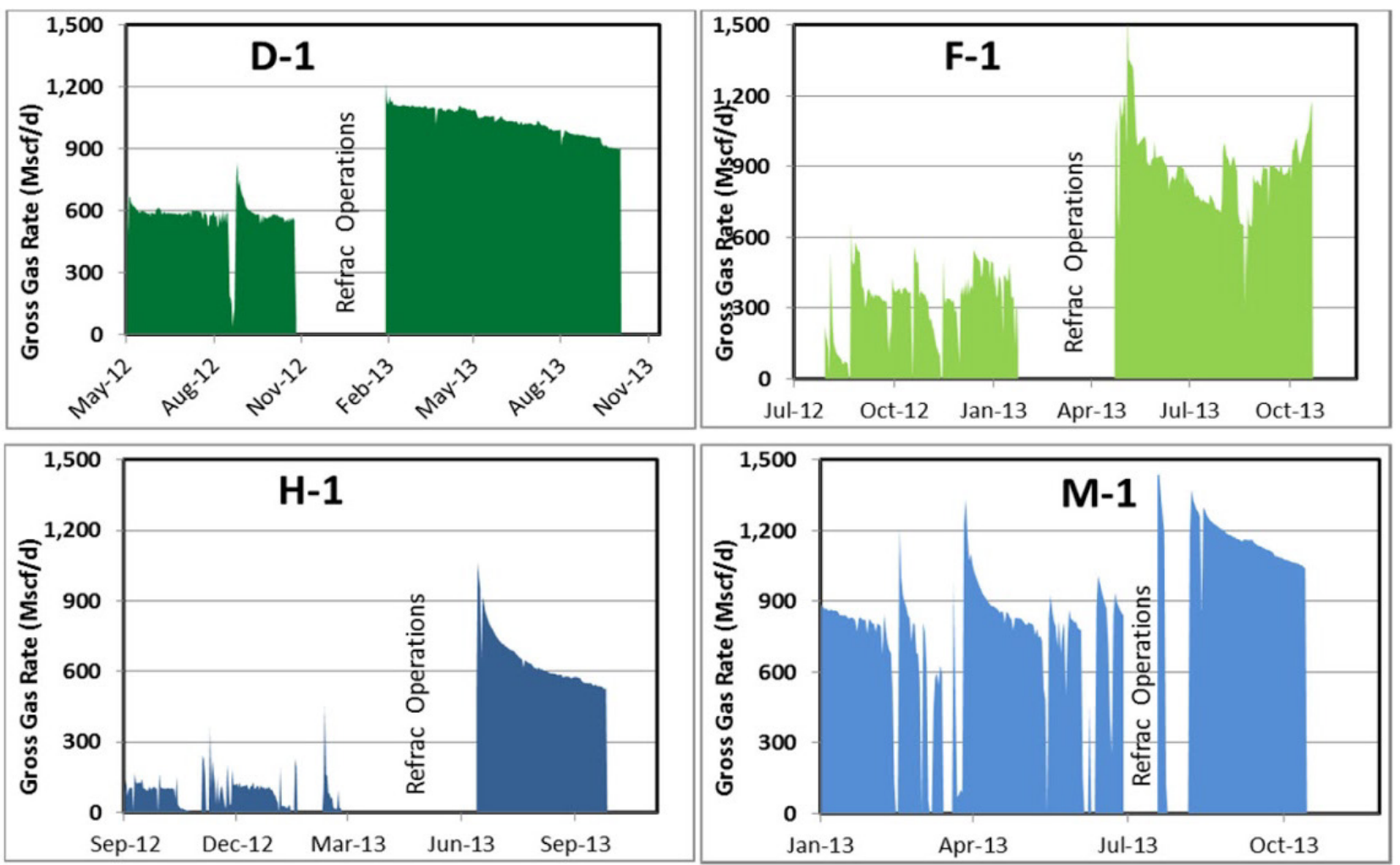

Figure 3. Pre- and Post-Re-fracturing Production Rates by Well. (3)

In fact, many shales exhibit steep productivity declines as high as $60-80$ percent in a year (Jayakumar etal, 2010). Additional factors include proppant crushing, embedment, low reservoir permeability, and ineffective initial fracturing (9).

In order to be effective with refracturing, the following tools can be used in a horizontal well:

- Sliding sleeve

- Coiled Tubing tools
- Perforation Squeeze (perf squeeze)

- Mechanical and Chemical Diverters

A case study in the Marcellus shale in southwestern Pennsylvania involved using a new temporary sealing agent along with chemical and mechanical diverters. The diverting agents entered the perforations and bridge-off and resulted in a long seal that accommodated the multiple shut-downs during existing perforations. The diverting agents directed the fracture fluid to the new clusters (9). 


\section{Pre-stack Seismic Inversion \& Reservoir Characterization in Unconventionals}

The two key properties derived from seismic are Young's modulus and Poisson's ratio. In addition, azimuthal inversion and AVO can be used to determine both the principal stresses and the differential horizontal stress radio. Specifically, wide-angle, wide-azimuth (WAZ) seismic data can be used to determine principle stresses (vertical, maximum and minimum horizontal), along with rock strength. (10)

The benefits include:

- Sweet spot identification

- Well location optimization

- Completions optimization

- Geochemistry (reservoir characterization - what do you have?)

- Basin analysis (big picture)

- XRD / XRF (while drilling)

- Drilling fluid optimization

\section{New Reservoir Stimulation Approaches}

Geochemistry and geomechanical data should be integrated in order to develop effective reservoir stimulation.

Currently, research is being directed in the area of nano-stimulation; that is, charged nano-particles are sent into the interstices of the clay minerals in order to stimulate them and accelerate the process of adsorption, and releasing gas molecules. Recent studies have demonstrated that nanoparticle-stabilized emulsions and forms can be utilized to recover oil and gas, particularly in mature fields.

A summary of current areas that have shown high potential for having a positive impact on reservoir stimulation include the following areas:

- Cation exchange capacity (stabilizing fluids introduced into the reservoir in order to avoid behaviors of clay minerals)

- Simulating charged particles (nano-stimulation)

- Production issues (focusing decline curves)

- Pressure controls / gas drive maintenance

- Punctuated refracturing at certain intervals
- Cluster spacing analysis to optimize induced fractures

- Fracture interference by design to optimize fracture networks

\section{Part II: North American Plays: "Best Practices" and Responses to the late 2014 through early 2016 Price Collapse}

A brief review of key shale and unconventional plays in North America allows one to see the emergence of certain "best practices." The following plays are reviewed briefly in terms of new develops and lessons learned.

- Bakken and Three Forks

- Eagle Ford

- Marcellus

- Mississippian Lime

- Woodford Shale

\section{Bakken \& Three Forks}

The Upper and Lower Bakken shales constitute source beds for the entire petroleum system (Bakken) in the Williston Basin of Montana and North Dakota. Optimizing the production in the Middle Bakken formation that lies between the Lodge Pole and the Three Forks formations has been achieved by taking a multi-disciplinary approach. (11)

- Extend the limits of pad drilling \& laterals by altering the horizontal landing targets and increasing wellbore lateral lengths

- Optimizing completion techniques: control and refine pumpdown procedures and flush procedures

- Completion design optimization:

- Proppant optimization (higher strength, ideal size). Optimizing proppants involves selected the one that is appropriate for the lithology.

- Frac fluid optimization

- Frac height determination

- Frac interference determination

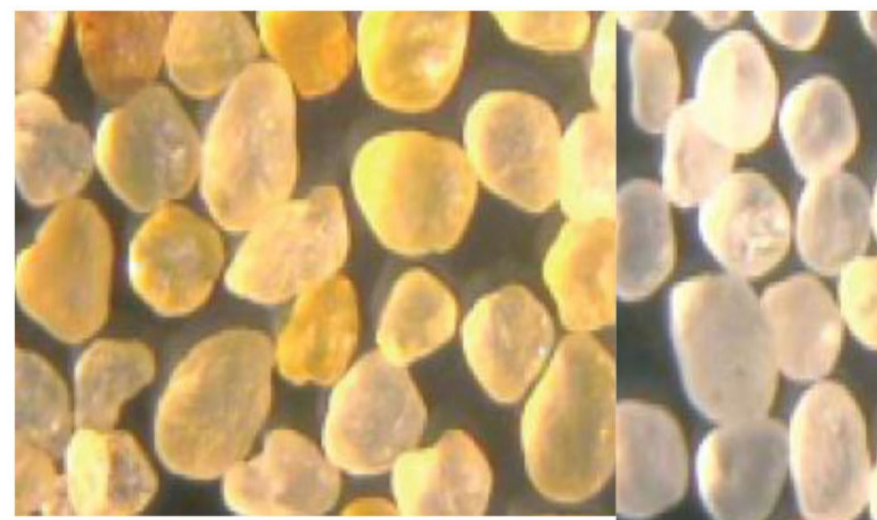

(a)Brown Sand (b) White Sand

Figure 4. Three types of proppants

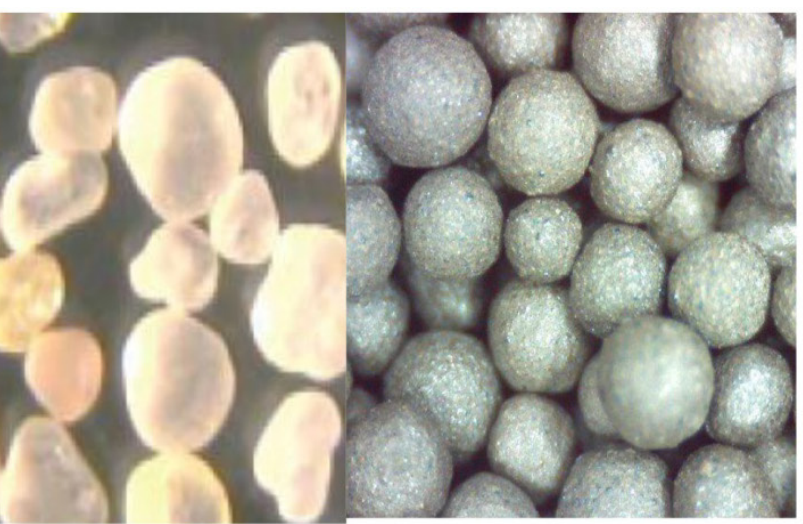

(c) Ceramic 
With the price of oil dropping as low as \$26 per barrel in early 2016, much of the activity in the Bakken slowed dramatically due to uneconomic conditions as well as operators in distress due to liquidity, debt, as well as uneconomic operations. Strategies changed and while operating efficiencies remained important, many companies such as Continental Resources made the decision to drilling but not complete. The multi-stage hydraulic fracturing would be postponed in order to wait for the price of oil to recover to a minimum of $\$ 60$ per barrel. (29)

Companies are looking very closely at optimizing the frac staging, and have noticed that the recovery per stage can be highly variable. High-strength proppant is used to retain long-term conductivity and to try to optimize the reserve recovery per stage (and per well). The problem is that in a well that has been drilled, but then maintained without completing for more than a year and up to two years, the potential formation damage can be rather significant, as well the potential for problems in the tubing. If there is much water, there can be additional concerns.

\section{Eagle Ford}

Because of its complexity and high degree of heterogeneity, the Eagle Ford requires an emphasis on optimizing reservoirs by means of identifying sweet spots, and then developing drilling and completion programs that maximize induced fractures, fracture networks, and fluid flow. The first priority is to identify sweet spots, which are characterized by relatively high Total Oil Content (TOC), relatively high brittleness, relatively high porosity, low clay content (which tends to create ductility), mineral filled natural fractures (for better possibilities of induced fractures, and an optimal stress regime.)

A sweet spot in the Eagle Ford is also an area of preferential enrichment, and the initial production levels can be average 2,000 barrels of oil per day in the first months of production, while a relatively barren area might produce only 200 barrels per day.

Geosteering using "logging while drilling" and image logs is very important. In addition, techniques to identify sweet spots can include the following:

- XRD / XRF: Geosteering in the laterals for sweet spots, as well as in pilot holes: The XRD data is particularly helpful in the determination of total clay, while the XRF measures 10-12 major elements, as well as trace elements (trace metals may indicate areas of high TOC (12)

- Chemostratigraphy: using major, minor, and trace element geochemistry to classify strata and to characterize them by means of correlations to sweet spots. It can be used to detect and evaluate subtle yet rapid change in superficially homogeneous rocks (13)

- Geomechanical data derived through pre-stack seismic inversion (13)

- Redox-sensitive metals are an excellent proxy for organic richness (14)
- Microseismic for determining fracture heights

- Pyrolysis includes determining free hydrocarbon, remaining hydrocarbon generation potential, organic richness (TOC), and Thermal Maturity (Tmax)

- Sequence Stratigraphic correlations: 3D seismic \& depositional modeling

As a result, the main performance determinants for the Eagle Ford are the levels of Vclay (ties to brittleness) and TOC, metal trace elements (proxies for organic content), mechanical elements (from inversion and mapping), multi-attribute analysis to determine best locations for induced fractures.

In a very low price environment, the Eagle Ford's heterogeneity has resulted in a great deal of reassessment with respect to acreage positions and the willingness to try to innovate with new completion and stimulation techniques. In addition, some of the extension plays have been deemed uneconomic. For example, the Eaglebine, which was considered to be an extension of the Eagle Ford and the Woodbine in East Texas, was determined to be uneconomic, even at $\$ 75$ per barrel. What that means in practical terms is that large acreage positions that seemed to have potential in 2011 - 2013 have been languishing since late 2014 .

The Pearsall shale, which is Cretaceous in age and sits below the Eagle Ford was attractive in the southwest part of the Eagle Ford play, and the companies that pursued it included Cabot, EOG, Murphy, Rosetta, and Valence. The play did not have sufficient success, although the possibilities of having a "stacked play" with multiple zones in the same lease appeared attractive.

In the future, it's possible that the Pearsall will again be a target, especially in areas where the infrastructure is already in place and laterals can be drilled from the same pad, in the same plays that are producing from the Eagle Ford or even the Austin chalk.

\section{Marcellus \& Utica}

Optimizing the Marcellus requires a deep understanding of the geology, particularly the depositional history, the thermal history of the basin, and also the structural history. The history combined with all available data can help one gain an ability to pinpoint sweet spots and also design programs with the right types of fluids. Using petrophysical data, core information, as well as seismic, it is possible to build 3D shared earth models, which can serve as static models for reservoir simulation (15)

In the Marcellus geochemistry is critical, particularly when targeting an ideal mix of gas and liquids.

This slide lists a few of the "must have" elements and the "best practices" in the play.

- Gas - Liquids boundary determinations

- Gas typing and understanding the migration history / patterns / mixing

- Accessible and non-accessible porosity

- Pore typing (tie back to regional studies)

- CT scans on the cores 
- In a difficult price environment, the Marcellus requires much thinking. With more pipelines to serve the Northeast market and more natural gas used for generating electricity, Marcellus gas still has some demand. However prices for the Marcellus gas continue to drop, in tandem with low oil prices for the Utica.

- Marcellus optimization in a low price environment involves identifying the wells that can be choked back without losing the drive and destroying the reservoir. It also involves using hedges and taking advantage of Contango situations with futures to develop a counter-cyclical hedge strategy, and to assess financial risk as astutely as possible.

\section{Mississippian Lime}

The Mississippian Lime in Oklahoma and Kansas is highly heterogeneous, and there is significant variability of oil saturation. For example, it is not unusual for a well to encounter $15 \%$ oil cut, but less than a mile away, a well completed in the same zone will encounter 2 percent oil cut. Watney (16) has investigated the distribution of oil saturation and has found that the knowledge of the geological history is critical in determining patterns for preferential enrichment. Higher oil cut is generally found in areas with fracture networks that include open fractures, and these communicating fracture networks correspond to areas of repeated tectonic activity, resulting in structural deformation. (16)

Much of the variability has to do with hydrothermal fluid flow. Goldstein and King (17) have found that there were three distinct pulses of hydrothermal fluid flow, each of which is associated with fracturing, silica dissolution and carbonate dissolution. Further, the hydrothermal fluid flow resulted in significant diagenesis, which allowed porosity to develop, as well as fracture networks. The combination of factors resulted in differential / preferential enrichment of oil and gas in the reservoir rocks (Goldstein and King, 2014).

In order to characterize the reservoirs, the following are needed:

- Image Logs for Fracture networks

- Basin-Level Analyses

- Petroleum Generation

- Expulsion / Flow

- Structure (Faults / Fracture Networks)

- Convergence with Mississippi Valley-Type Mineralization

The Mississippian Lime has played an important part of the STACK play in central Oklahoma, where it offers another productive zone for low incremental cost. It is the Mississippian-age Meramec group that is largely carbonate. As a survival strategy, companies have looked at the Mississippian as ideal if it produces in conjunction with other zones (mainly Pennsylvanian sands, but potentially also with a shale play such as the much deeper Woodford). As a "stand-alone" play of great extent, the fact that there is so much co-produced water (as much as 99\%) creates enormous disposal costs as well as environmental liability, not only for the water itself, but for the injection process, which is blamed for the explosion of seismic activity in Oklahoma, much of which is centered around areas with high-volume saltwater disposal operations (injection wells into the Arbuckle Lime) and which deals with produced water from the Mississippian lime.

\section{Woodford Shale}

The Woodford shale is found over a large geographical extent, and must be studied very carefully to identify the limits of fracability as well as the extent of the oil window (18).
- Geomechanics
- Pore pressure regimes
- Nano-geomechanics (cation exchange capacity)
- Fracture typing / characterization
- Fracture networks
- Brittleness \& Fracability determination

The productive extent of the Woodford has been expanded recently, thanks to an enhanced understanding of the relationship between different types of kerogen and thermal maturation (18). In order to determine the prospectivity of an area, certain geochemical evaluations can be very helpful. They include the following:
- Geochemistry
- Total Organic Content (TOC) evaluations
- Kerogen typing
- Maturity / Vitrinite reflectance
- Gas fingerprinting
- Migration patterns
- Indicator minerals / deformations
- Adsorption factors
- Pyritization

The Woodford shale can achieve very high production, and the decline curves can be less steep than in other plays. However, the variability of the fracability of the shale affects the ultimate recoverable reserves, which makes it necessary to focus on sweet spot identification and optimizing the hydraulic fracturing.

Possibly most important in a low price environment is a hedge strategy, not just financial hedging but with back-up zones. The "stacked pay" potential in the Woodford play consists of the Springer group (the Goddard and the Boatright) and also the potential for shallow Pennsylvanian sands, such as those that produce in the Velma field in southern Oklahoma.

At the same time, innovative and even "fringe" techniques for optimizing production, or revitalizing production after the initial production has declined, are likely to find at least initial acceptance, if the costs are low enough, and the option is to plug and abandon a horizontal well. Some of the more extreme ideas for revitalizing horizontals have less to do with restoring drive / pressure and more to do with reopening 
fracture networks and enhancing conductivity. Deliberately induced and highly targeted seismicity is one such technique, albeit one that is met with a bit of skepticism given that the induced seismicity due to injection wells has had the effect of closing rather than stimulating fracture-based production in some cases.

\section{Conclusions}

In a low price environment, "factory drilling" and the notion that one can make money producing very low-quality reservoirs, and focusing on quantity vs. quality are suddenly problematized. The challenge becomes one of evaluating risk and strategically aligning one's drilling efforts with an overall plan that involves drilling but not completing, targeting acreage with "stacked" pay (including bypassed pay), and developing a list of actions for each price point.

- New technologies and new techniques are being evaluated every day, and new service companies will emerge as new low-cost revitalization or optimization strategies are proven. The companies with too much overhead or an inability to diversify are likely targets for takeover (or oblivion).

- New approaches to sweet spots (whipstocked laterals and refracturing) can result in optimized reservoirs; however, in a low price environment whipstocking and refracturing are usually not economic, and other approaches will be tried in order to stimulate production. In horizontals, it's often an "all or nothing" and very high-stakes initial completion because going back in and trying to remediate / correct a flawed frac job in a 10,000 foot lateral is extremely costly and likely not to be effective. That said, there are techniques that are tried in conjunction with nearby completions that can potentially stimulate production in nearby laterals. However, the activity that stimulates can also damage.

- New reservoirs and also stacked pays are possible, particularly when migration paths can be traced by means of understanding fracture networks. In this case, the migration pathways can indicate selective enrichment, and in theory can be detected using surface geochemistry.

- Manipulating the clay minerals on a nano level can "unbind" the matrix and allow more accessible porosity. It is recommended that these approaches are tried first on vertical wells to test the concept.

- Managing drilling fluid chemistry can be done to avoid formation damage and to enhance brittleness and effectiveness of stimulation (including hydraulic fracturing)

In a low price environment, the general tendency is to follow a very conservative approach and avoid dedicating capital to activities that may not have a clear payout. At the same time, it's possible to take a look at horizontal wells that have declined to the point that they should be plugged and abandoned. The plugging and abandoning costs for horizontals can be quite expensive, which makes looking at potential revitalization strategies cost-effective.

If it is possible to revitalize a well that is no longer producing for less than the cost of plugging and abandoning, then there is quite a bit of potential. This is a strategy that has been implemented quite well for vertical wells. It is economically propitious, particularly if there is a price increase of at least 30 percent.

Unfortunately, the options are limited for revitalizing horizontal wells that are technically and legally at the point of plugging and abandoned. Most of the strategies for revitalizing horizontals have to do with refracturing, which can be extremely expensive. Companies that perfect techniques and technologies for revitalizing horizontal wells at a relatively low cost will position themselves to be leaders of the future.

\section{REFERENCES}

[1] Peschier, L. The Boquillas (Eagle Ford) formation of South Texas: potential outcrop analogs for nonconventional Eagle Ford shale reservoirs in the subsurface. Houston Geological Society Bulletin. 2010 Mar; 52(7):29,31,33,39

[2] Broussard, A. N, Templeton, G. W., Travis, D. Whipstock-and-inflatable packer combination decreases openhole sidetracking costs in central Arkansas. Society of Petroleum Engineers. 2009. SPE 123577-MS.

[3] French S, Rodgerson J, Feik C. Re-fracturing horizontal shale wells: case history of a Woodford Shale pilot project. Society of Petroleum Engineers. 2014 Feb 4. DOI:10.2118/168607MS

[4] SandRidge Energy. Q3'14 Operations Update. 2014 Nov 6. Available from:

http://investors.sandridgeenergy.com/files/doc_presentations /LM110614-Q3\%2714-Slides-\%28Final\%29.pdf

[5] Al-Arfaj MK, Hossain E, Sultan A, Amanullah M, Al-Fuwaires O, Al-Subai T. Preliminary test results of inhibitive water-based muds used to mitigate unconventional shale drilling problems. International Petroleum Technology Conference. 2014 Dec 10. DOI:10.2523/17800-MS

[6] Al-Arfaj MK, Amanullah M, Sultan AS, Hossain ME, Abdulraheem A. Chemical and mechanical aspects of wellbore stability in shale formations: a literature review. Society of Petroleum Engineers. 2014, Nov 10. DOI:10.2118/171682-MS

[7] Emadi H, Soliman MY, Samuel R, Heinze L, Moghaddam RB, Hutchison S. An experimental study of the swelling properties of unconventional shale oil rock samples using both water-based and oil-based muds. Society of Petroleum Engineers. 2014 Oct 27. DOI:10.2118/170686-MS

[8] Jayakumar, S., Lane, R. H. Delayed crosslink polymer gel system for water shutoff in conventional and unconventional oil and gas reservoirs. SPE International Symposium on 
Oilfield Chemistry. 2013 April 8 - 10 http://dx.doi.org/10.2.2118/164046-MS.

[9] Arnold DM, Boulis A, Fragachan FE. Eco-friendly biodegradable materials for zonal isolation of multiple perforation clusters during refracturing of a horizontal well: case history from Marcellus Shale hydraulic fracturing. Society of Petroleum Engineers. 2014 Oct 21. DOI:10.2118/171015-MS

[10] Gray D, Anderson P, Logel J, Delbecq F, Schmidt D. Principle stress estimation in shale plays using 3D seismic. CSPG Geoconvention, May 10-14, 2010. AAPG Search and Discovery. 2010. Art. No.: 90172. Available from: http://www.searchanddiscovery.com/pdfz/abstracts/pdf/2014 /90172cspg/abstracts/ndx_gray.pdf.html

[11] Hardriker J, Besler MR, Barham M, Mahrer KD, Micheli T. Optimized production in the Bakken Shale: South Antelope case study. URTeC: 1913075. 2014. DOI: 10.15530/urtec-2014-1913075.

[12] Tonner D, Hashmy KH, Abueita S, Jonkers J. Focusing stimulation efforts on sweet spots in shale reservoirs for enhanced productivity. AAPG International Conference and Exhibition, Singapore, Sept 16-19, 2012. AAPG Search and Discovery. 2012.

[13] Tinnin B, Bello H, McChesney M. Multi-source data integration to predict well performance: Eagle Ford sweet spot mapping. Eagle Ford plus Adjacent Plays and Extensions Workshop, Feb 24-26, 2014, San Antonio, TX. AAPG Search and Discovery \#41397. 2014.

[14] Dix MC, Spain DR, Sano JL, Ratcliffe KT, Hughes SN, Casarta NG, Buller D. Application of whole rock elemental data in shale gas development: an example from the Jurassic Haynesville Formation. European Association of Geoscientists and Engineers International. 2010. p. Abstract 38937.

[15] Yang C, Bowman D, Morris J, Zagorski B. Marcellus shale asset optimization through increased geological understanding. AAPG Annual Convention and Exhibition, Pittsburgh, PA, May 19-22, 2013. AAPG Search and Discovery. 2013. Art. No.: 41144.

[16] Watney L. Fluid migration and accumulation within the Mississippian: why $2 \%$ oil cut here, $15 \%$ oil cut one mile away? AAPG Mississippian Lime Forum, Oklahoma City, OK, Feb 20, 2014. AAPG Search and Discovery. 2014. Art. No.: 50953. Available from: http://www.searchanddiscovery .com/pdfz/documents/2014/50953watney/ndx_watney.pdf.ht $\mathrm{ml}$

[17] Goldstein R, King B. History of hydrothermal fluid flow in the Midcontinent: A key to understanding the origin and distribution of porosity. AAPG Mississippian Lime Forum, February 20, 2014. AAPG Search and Discovery. 2014. Art. No.: 50958. Available from: http://www.searchanddiscovery .com/pdfz/documents/2014/50958goldstein/ndx_goldstein.p df.html

[18] Cardott B. Woodford shale play update: expanded extent in the oil window. AAPG Woodford Shale Forum, May 29, 2014.
AAPG Search and Discovery. 2014. Available from: http://www.searchanddiscovery.com/documents/2014/80409 cardott/ndx_cardott.pdf?q=\%2BauthorStrip $\% 3$ Acardott

[19] Ansari RZ, Yadav H, Thiruvenkatanathan P, Zett A, Spain DR, Gysen A. Advanced petrophysical surveillance improves the understanding of well behavior in unconventional reservoirs. Society of Petroleum Engineers. 2014 Oct 27. DOI: 10.2118/170878-MS.

[20] Hu D, Matzar L, Martysevich VN. Effect of natural fractures on Eagle Ford Shale mechanical properties. Society of Petroleum Engineers. 2014 Oct 27. DOI: 10.2118/170651-MS.

[21] Lalehrokh F, Bouma J. Well spacing optimization in Eagle Ford. Society of Petroleum Engineers. 2014 Sep 30. DOI: 10.2118/171640-MS.

[22] Landry C, Eichhubl P, Prodanovic M, Tokan-Lawal A. Matrix-fracture connectivity in Eagle Ford Shale. Society of Petroleum Engineers. 2014 Aug 28. DOI: 10.15530/urtec-2014-1922708.

[23] Sanaei A, Jamili A. Optimum fracture spacing in the Eagle Ford gas condensate window. Society of Petroleum Engineers. 2014 Aug 28. DOI: 10.15530/urtec-2014-1922964.

[24] Sookprasong PA, Hurt RS, Gill CC. Downhole monitoring of multicluster, multistage horizontal well fracturing with fiber optic distributed acoustic sensing (DAS) and distributed temperature sensing (DTS). International Petroleum Technology Conference. 2014 Dec 10. DOI: 10.2523/17972-MS

[25] Yang M, Economides MJ. Natural proppants for hydraulic fracture production optimization in Barnett and Eagle Ford Shales. Society of Petroleum Engineers. 2012 Jan 1. DOI: 10.2118/153811-MS.

[26] Yoshida N, Zhu D, Hill AD. Temperature-prediction model for a horizontal well with multiple fractures in a shale reservoir. Society of Petroleum Engineers. 2014 Nov 1. DOI: 10.2118/166241-PA.

[27] Yu J, An C, Mo D, Liu N, Lee, RL. Study of adsorption and transportation behavior of nanoparticles in three different porous media. Society of Petroleum Engineers. 2012 Jan 1. DOI: $10.2118 / 153337-\mathrm{MS}$.

[28] Zhang J, Ouyang L, Hill AD, Zhu D. Experimental and numerical studies of reduced fracture conductivity due to proppant embedment in shale reservoirs. Society of Petroleum Engineers. 2014 Oct 27. DOI:10.2118/170775-MS

[29] OGJ Editors. Continental Resources to defer completion activity, cut Bakken rigs. Oil\&Gas Journal. 2015 Sept 9. http://www.ogj.com/articles/2015/09/continental-resources-t o-defer-completion-activity-cut-bakken-rigs.html

[30] Krauss, C. Hoping for a price surge, oil companies keep wells in reserve. The New York Times. 2015 Dec 25. http://www.nytimes.com/2015/12/26/business/energy-enviro $\mathrm{nment} /$ hoping-for-a-price-surge-oil-companies-keep-wells-in -reserve.html?_r=0 